\title{
Santolaya Machetti, Pablo, Procedimiento y garantías electorales, Navarra, Instituto Derecho Parlamentario, Civitas, Thomson Reuters, 2013, 187 pp.
}

Se trata de un libro de lectura obligada para el lector mexicano interesado en los estudios electorales comparados, no sólo por los temas que aborda sino por el conocimiento especializado que sobre el tema tiene el autor, en el cual coincide la triple calidad de integrante de la Junta Electoral Central de España - cargo que ocupa desde 2004-, así como de autor de otros libros sobre la materia y docente de la asignatura Procedimientos y Garantías Electorales en el Master de Derecho Parlamentario, Elecciones y Estudios Legislativos que imparte el Instituto de Derecho Parlamentario de la Universidad Complutense de Madrid.

En rigor, el libro analiza la aplicación de la Ley Orgánica del Régimen Electoral (LOREG), aprobada inicialmente el 19 de junio de 1985, reformada hasta la fecha en 18 ocasiones - la más reciente el 15 de julio de 2011 -, en aspectos estrictamente procedimentales. El análisis abarca los siguientes cinco aspectos básicos: administración electoral; censo electoral; presentación y proclamación de candidaturas; campaña electoral y proclamación de electos. Puesto que se trata en los hechos de un libro de texto destinado a la asignatura del mismo nombre, se entiende que los otros aspectos que regula la LOREG son tratados en otra asignatura del mismo Master, denominada Sistema electoral en España. 
Para el lector mexicano no familiarizado aún con el derecho electoral y el derecho procesal electoral español es conveniente revisar primero los ordenamientos españoles respectivos, a efecto de adentrarse al libro una vez conocido el contexto constitucional y legislativo de los múltiples casos técnico-jurídicos que aborda. Desde luego que quien prefiera iniciar la lectura sin estas referencias podrá encontrar cierta aridez técnica en el texto pero cuya lectura le será igualmente aleccionadora porque de cualquier forma podrá tomar como referencia de los casos que se apuntan la legislación electoral y procesal electoral mexicana.

Ciertamente, el Código Federal de Instituciones y Procedimientos Electorales y la Ley General del Sistema de Medios de Impugnación en Materia Electoral de nosotros regulan, de una parte, lo relativo a registro federal de electores, precampañas y campañas electorales y declaraciones de validez, y de otra parte, los medios de impugnación de los actos y resoluciones de la autoridad electoral administrativa. La lectura nos arroja de inmediato las diferencias institucionales que al final resultan no ser tantas y que, las propuestas de reforma en curso en España y México parecen acercar aún más los dos sistemas electorales y de impugnación electoral. Por ejemplo, en México, las propuestas ya no tan recientes de un código penal único y de una autoridad electoral nacional.

No obstante, en principio somos una federación en tanto que en España hay una administración centralizada atenuada por las provincias autónomas, pero además en España tienen las elecciones de la Unión Europea de la que forman parte, por lo que el autor se refiere a los siguientes tipos de elección: diputados y senadores del Congreso, municipales, parlamentos autonómicos y del Parlamento Europeo.

\section{Administración electoral}

A diferencia de nosotros, en España no hay ninguna referencia en la Constitución respecto a la organización de la autoridad electoral administrativa, situación que el autor no deja de señalar y manifestar su extrañeza puesto que - afirma - las funciones electorales satisfacen una finalidad "de indudable relieve constitucional". La Administración electoral se compone exclusivamente por las juntas electorales, Central, Provincial y de Zona, así como por las Mesas electorales. 
La Oficina del Censo Electoral "es un organismo gubernamental pero ejerce sus competencias bajo la dirección y supervisión de la Junta Electoral Central". Se trata de un diseño organizacional extraño a nosotros que le permite al autor afirmar que "aún sin formar parte de la Administración electoral en sentido estricto, la Administración del Estado organiza materialmente los procesos electorales en España”. Pues además, por ejemplo, el Ministerio de Asuntos Exteriores, a través de las oficinas consulares forma el Censo de Residentes Ausentes; la sociedad estatal Correos y Telégrafos interviene para el envío de la propaganda electoral y el voto por correspondencia; el Ministerio de la Presidencia, del que depende el Centro de Investigaciones Sociológicas que elabora las encuestas electorales oficiales: el Ministerio de la Defensa se encarga de la gestión del voto del personal embarcado y de los componentes de las misiones internacionales, pero sobre todo es el Ministerio del Interior, a través de la Dirección General de Política Interior, el "que se encarga, entre otras relevantes funciones, de garantizar el material electoral y de ofrecer los resultados oficiosos de las elecciones la misma noche de los comicios".

Por extraño que nos parezca a los mexicanos, en España "no existe un órgano que asuma la totalidad de las competencias gubernativas en materia electoral, ni tampoco alguien que asuma, de manera real y efectiva una función jerarquizada de dirección e impulso de los diferentes organismos". El autor señala los intentos para que esta coordinación esté a cargo de la Dirección General de Política Interior mencionada, pero puesto que carece de los instrumentos necesarios para asegurar dicha función, el autor se queja de "algunas dosis de descoordinación”. Es por ello que el autor propone que el director general de política interior, al igual que lo hace el director de la Oficina del Censo Electoral, "participara en las reuniones de la Junta Electoral Central con voz pero sin voto".

Existe, como ya se ha señalado, una Junta Electoral Central, con competencia en todo el territorio nacional; las Juntas Provinciales, situadas en las capitales de provincia; las Juntas de Zona, correspondientes a los partidos judiciales existentes conforme a la división judicial del país (sin embargo, los partidos judiciales creados con posterioridad a las elecciones locales de 1979 no constituyen zonas electorales), y las Juntas de Comunidad Autónoma.

La integración de la administración electoral tiene un carácter mixto ya que en su integración hay tres miembros provenientes de origen 
Esta revista forma parte del acervo de la Biblioteca Jurídica Virtual del Instituto de Investigaciones Jurídicas de la UNAM

judicial elegidos por sorteo "entre los magistrados de las Audiencias Provinciales para las Juntas Provinciales, entre los Jueces de Primera Instancia o Instrucción para los de Zona, y dos Vocales Juristas designados a propuesta de las fuerzas políticas contendientes en las elecciones"; todos los cuales son inamovibles. Los secretarios de las Audiencias y Juzgados correspondientes actúan como secretarios, y a las Juntas Provinciales se agrega con voz pero sin voto el delegado provincial de la OCE. Por todo lo anterior el autor les asigna la naturaleza de órganos arbitrales de un carácter cuasijudicial.

La tercera característica de este modelo de Juntas Electorales, es que con excepción de la JEC, es que la administración electoral es una estructura estrictamente temporal. Asimismo, el autor advierte un carácter progresivamente más centralizado de esta estructura, tendencia que ejemplifica con la facultad de revocar de oficio o a instancia de parte las decisiones de las juntas provinciales y de Comunidad autónoma "cuando se opongan a la interpretación de la normativa electoral realizada por la JEC", además de que las consultas formuladas a ésta tienen carácter "vinculante". Todo esto convierte, según el autor, a la JEC en el órgano capital de la Administración electoral.

En el análisis de la JEC, respecto a su situación en el esquema de división de poderes, son varias las respuestas posibles. La primera de ellas es que se trataría de un órgano de la esfera parlamentaria, toda vez que según afirma el autor, en el derecho español la actividad de control de las elecciones nace como una función auxiliar del Parlamento. Además, la dotación de recursos personales y materiales a la JEC corresponde a las Cortes Generales, y su secretario es el secretario general del Congreso de los Diputados. Además, celebran sus sesiones en el Congreso por ser el lugar donde ejerce su cargo su secretario, así como porque una parte de sus miembros, los académicos - 5 de 13-, son designados por el Congreso de los Diputados a propuesta conjunta de los grupos políticos.

En oposición a esta perspectiva, el autor recuerda que la mayoría de sus miembros no son elegidos en sede parlamentaria, que son inamovibles, que no están sometidos a controles parlamentarios y que no reciben instrucción alguna del Congreso de los Diputados para realizar su actividad. De ahí que otra respuesta posible sea considerar que forma parte del Poder Judicial, en virtud, en primer lugar, de su composición mayoritariamente judicial pues ocho de sus trece miembros son magistrados del Tribunal Supremo, así como por la inamovilidad 
Esta revista forma parte del acervo de la Biblioteca Jurídica Virtual del Instituto de Investigaciones Jurídicas de la UNAM

de los miembros, la ausencia de dependencia de cualquier otro órgano y las garantías que protegen su imparcialidad y objetividad, además de que su función es la de resolver conflictos, función en sí misma más cercana a la jurisdiccional. Es por todo esto que en la doctrina española se haya hablado de un órgano cuasijudicial.

Sin embargo, puesto que los actos de la autoridad electoral son recurribles ante los tribunales $y$, según el autor, los actos sometidos a revisión judicial necesariamente deben ser considerados "actos administrativos". A partir de estas afirmaciones y de criterios sostenidos al efecto por el Tribunal Constitucional, el autor señala que "la doctrina dominante en España ha considerado que la Junta Electoral es una Administración independiente, subrayando incluso que se trata del mejor ejemplo de este tipo de Administraciones por su alto grado de independencia funcional con relación al Gobierno".

La cuarta respuesta posible adelantada por el autor es que se trata de un órgano constitucional al margen de la separación de poderes, con la salvedad a su vez que la Constitución Española no se refiere en momento alguno a la JEC. De ahí que en opinión del autor no quepa más que una respuesta empírica y poco doctrinal, para considerar que tiene una "naturaleza especial", que es una "administración ad hoc" con funciones de garantía, que es una "Administración peculiar y compleja", donde hay magistrados designados por sorteo y catedráticos elegidos por las fuerzas políticas, todos ellos inamovibles como ya se ha señalado.

Es importante destacar que el sorteo mencionado se produce entre magistrados de todos los órdenes jurisdiccionales (civil, penal, laboral y militar), lo que hace que para muchos de ellos sea una primera experiencia en la materia electoral. También, que por cuanto a la designación de los vocales no judiciales en rigor no los elige el pleno del Congreso sino a través de un mecanismo que permite un acuerdo conjunto entre todas las fuerzas parlamentarias para su nombramiento en un plazo determinado, transcurrido el cual los nombramientos se hace por la Mesa de la Cámara, "oídos los grupos políticos y en consideración a la representación existente en el seno de la Cámara”.

Se trata de nombramientos sometidos a requisitos objetivos (expertos en materia electoral provenientes del derecho constitucional y en menor medida del derecho cdministrativo, "sobre los que se procura un amplio acuerdo parlamentario, pero que, en definitiva, responden a propuestas partidistas". Los candidatos no judiciales que analizamos 
ahora tienen que comparecer ante la Comisión Consultiva de Nombramientos, presidida por el presidente del Congreso e integrada por los Portavoces de los Grupos Parlamentarios; Comisión que emite un informe de idoneidad de los candidatos. No obstante las peculiaridades anotadas, el autor coincide con la doctrina dominante en el sentido de que se trata de un modelo consolidado de integración de la Administración electoral, "un indiscutible éxito institucional que parece destinado a permanecer", respecto del cual el autor no deja de señalar "algunos riesgos para el sistema" que en seguida son expuestos de manera breve.

El primer riesgo que señala el autor es la suspensión cautelarísima por parte del Tribunal Supremo de acuerdos de la JEC cuando, por ejemplo, en el caso de campañas electorales, no existe un procedimiento específico de revisión contemplado en la LOREG, puesto que tal medida, comprensible desde el punto de vista de la tutela judicial cautelar efectiva, puede vulnerar el papel de la JEC como árbitro último de los procesos electorales. El segundo riesgo corresponde a la invasión que eventualmente la JEC podría hacer del campo del legislador, para lo cual propone que la Junta evite en el futuro innovar el ordenamiento jurídico. Lo que traducido al caso mexicano implicaría que la función reglamentaria no fuese más allá de las disposiciones legislativas. Finalmente, el tercer riesgo es que las fuerzas políticas pretendan utilizar a la JEC para solucionar problemas a los que institucionalmente no puede hacer frente.

\section{El censo electoral}

De entrada el autor recuerda las dos tendencias actuales para integrar el censo electoral, es decir, el registro federal electoral para nosotros: que la inscripción se produzca de oficio por las autoridades competentes mediante un proceso oficial no instado por los particulares; procedimiento compatible con la intervención de los particulares para revisar el censo e instar las inscripciones o modificaciones necesarias. Este es el caso español.

Señala desde luego otros casos, como el nuestro, en los que la inscripción depende de la iniciativa individual, sin la cual no se produce pero que es sin embargo obligatorio y es necesario concurrir a una oficina pública con la documentación necesaria. Distingue también entre los censos permanentes que se actualizan y los que se hace ex 
novo para cada elección. En cualquier hipótesis, para garantizar validez y actualización de los datos es necesaria la comunicación entre los diferentes registros públicos en los que se reflejan hechos vitales de los ciudadanos que impactan en su derecho al sufragio. En el sistema español tales registros son los siguientes: padrón municipal, registros consulares y registro civil.

La Oficina del Censo Electoral, como su nombre lo indica, es la responsable de esta función en España; la LOREG la enmarca en el Instituto Nacional de Estadística, organismo autónomo dependiente del Ministerio de Economía, cuyo presidente tiene rango de subsecretario y puede ser nombrado o removido por el gobierno a propuesta del ministro de economía. Al efecto, el autor recuerda la tendencia observable en otros países en los cuales esta oficina se encuadra al interior de los propios órganos electorales, como sucede en México. Reconoce, por lo tanto, que también en este aspecto el modelo español puede ser considerado atípico.

No obstante que la OCE no se encuentra entre los componentes de la Administración Electoral, la LOREG establece que la OCE "ejerce sus competencias bajo la dirección y supervisión de la Junta Electoral Central"; dirección y supervisión que en opinión del autor "no es fácil concretar en qué consiste realmente", toda vez que la JEC no participa en la elaboración ni en la actualización del Censo, ni tiene competencia respecto de las reclamaciones individuales sobre inscripción en el censo. Sin embargo, la OCE está sometida a las instrucciones que dicte la JEC en materia censal, las cuales han sido 71 de 1985 a 2012.

Como sucede en México, el Censo electoral es el único para toda clase de elecciones, aunque en España se amplía con los extranjeros que tienen derecho a votar en las elecciones locales y al Parlamento europeo. El censo es un documento permanente que se actualiza mensualmente con referencia al día primero de cada mes; antes de 1975 su actualización era anual. Los mecanismos de reclamación están disponibles tanto para los interesados - cualquier persona respecto de sus datos censales - como para las fuerzas políticas. Está prohibida la información de los datos personales del censo salvo solicitud judicial. Fue a partir de 1999 que el Tribunal Constitucional incluyó entre los "interesados" a las fuerzas políticas partidos, federaciones o coaliciones electorales, en virtud de su interés para impugnar irregularidades del censo. 
El Censo electoral está compuesto por el censo de electores residentes en España, y por el censo de los electores residentes-ausentes que viven en el extranjero; ningún elector puede figurar simultáneamente en ambos. Hasta 2011 los españoles residentes en el extranjero podían votar y ser elegidos en todas las elecciones; a partir de ese año se elimina el sufragio de los residentes-ausentes en las elecciones municipales y se convierte en voto rogado el ejercicio del derecho de sufragio en los demás procesos electorales, esto significa que el elector deberá solicitarlo expresamente para cada proceso electoral.

Es importante señalar, como lo hace el autor, que la llamada Ley de Memoria Histórica aprobada en 2007, por la que se reconocen y amplían derechos a favor de quienes sufrieron persecución y violencia durante la guerra civil y la dictadura, permitió durante un periodo de dos años, la adquisición de la nacionalidad española, y su inmediata y de oficio conversión en electores, a los hijos de padre o madre españoles de origen y a los nietos de quienes perdieron o tuvieron que renunciar a la nacionalidad como consecuencia del exilio.

\section{Presentación y proclamación de candidaturas}

El procedimiento electoral en sentido estricto regulado por la LOREG, se inicia con la presentación de las candidaturas por parte de los representantes de los grupos políticos. Las Juntas Electorales competentes serán las provinciales para las elecciones al Congreso de los diputados y el Senado, las de Zona para las municipales y la Junta Electoral Central para las del Parlamento Europeo. Las fuerzas políticas que pueden presentar candidaturas son: partidos y federaciones políticas inscritas en el Registro del Ministerio del Interior. Es de mencionarse la extrema facilidad de inscripción de un partido político en el registro y, por el contrario, la práctica imposibilidad de realizar la cancelación de una inscripción, sea voluntaria o por sentencia judicial. El Registro de partidos políticos quedó así configurado, en especial por la jurisprudencia del Tribunal Constitucional, como instrumento sumamente respetuoso del derecho de asociación.

En el caso de los partidos extraparlamentarios existe el requisito de aportar un determinado número de firmas, según la nueva regulación establecida en 2011. Por su parte, la creación de una coalición entre partidos o federaciones de éstos, debe formalizarse ante la Junta Electoral competente, la JEC, salvo que su ámbito sea igual o inferior al de 
una provincia -Junta Provincial - o de un partido judicial —Junta de Zona-, dentro de los días siguientes a la convocatoria del proceso electoral. La regulación permite que la coalición sea para cada proceso electoral o para varios convocados en la misma fecha, e impide que los partidos coaligados presenten candidaturas independientes en el mismo proceso electoral y en la misma circunscripción. Es posible mantener una denominación común a todas las candidaturas de la coalición y adoptar una denominación específica adicional en determinadas circunscripciones.

Las agrupaciones de electores son definidas por el autor como las candidaturas presentadas por un determinado número de electores de una circunscripción que deciden avalar con sus firmas una determinada lista electoral en un concreto proceso electoral. Las dos notas más características son su carácter temporal, sólo para ese proceso electoral, y su carácter de candidatura independiente de cualquier otra que se presente en el mismo proceso en otra circunscripción, de forma que no es posible que exista coalición de agrupaciones de electores, ni tampoco de éstas con partidos políticos. Se admite la presentación de candidaturas por correo siempre que sea ante la Junta competente y dentro del plazo legal; no es necesario que los candidatos sean a su vez electores en esa determinada circunscripción.

La inelegibilidad es todo supuesto legal que priva del derecho de sufragio pasivo a una persona. Con respecto a las inelegibilidades el Tribunal Constitucional ha establecido que "la falta de capacidad jurídica para ser elegible no debe confundirse con el instituto jurídico de la inelegibilidad". El autor distingue entre inelegibilidades electorales e inelegibilidades penales; las primeras son de origen electoral cuando se excluye del sufragio pasivo a personas que por su lugar preeminente en la sociedad o por su intervención en el proceso pueden menoscabar la libertad o igualdad que deben presidir los procesos electorales democráticos, en tanto que las otras son consecuencia de una sentencia penal.

Con relación a las firmas necesarias para la presentación de determinadas candidaturas, antes de 2011 la situación era la siguiente: sólo en las elecciones al Parlamento Europeo eran necesarias 15000 firmas de electores o bien de 50 cargos (funcionarios) públicos representativos de cualquier instancia, desde miembros de las corporaciones locales hasta diputados del Parlamento Europeo. Las agrupaciones de electores, por razón natural, sí requerían de las 15000 firmas para 
Esta revista forma parte del acervo de la Biblioteca Jurídica Virtual del Instituto de Investigaciones Jurídicas de la UNAM

presentar candidatos; en éste y en la totalidad de los procesos electorales. En las elecciones generales, las agrupaciones de electores debían presentar la firma de un $1 \%$ de los electores de la circunscripción y en las locales un número de firmas que oscila entre este mismo tanto por ciento en los municipios de menos de 5000 habitantes y 8000 firmas en los de más del millón.

En opinión del autor estas normas eran consideradas insuficientes por el gran número de partidos políticos registrados y la inexistencia del requisito de presentar fianzas económicas para quien pretende concurrir a las elecciones y que sólo le fuese devuelta si supera un umbral mínimo de votos, como ocurre en muchos ordenamientos comparados. Todo esto daba lugar a un excesivo número de candidaturas con acceso a ventajas como un tiempo mínimo de publicidad electoral en medios públicos. Se dio el caso, incluso, de una candidatura que en realidad sólo tenía interés de acceder al censo electoral para utilizarlo ilícitamente con fines comerciales, aunque también las hubo sólo para reivindicar ciertos temas que eran retirados al final de las campañas y antes de las elecciones. De ahí la exigencia a partir de 2011 de que los partidos sin representación en alguna de las Cámaras avalaran sus candidaturas con la firma de al menos $0.1 \%$ de los electores inscritos en el censo electoral de la circunscripción; se trata ciertamente de un requisito diez veces menor que el exigido a las agrupaciones de electores.

Toda vez que la primera aplicación de esta nueva regulación se produjo apenas unos meses después de su aprobación, ante la absoluta ausencia de desarrollo normativo, la JEC dictó una instrucción con normas procedimentales muy detalladas, lo que no evitó una decena de sentencias del Tribunal Constitucional en el procedimiento de amparo sobre proclamación de candidatos.

Después de algunos antecedentes en leyes electorales de las comunidades autónomas que impusieron la paridad del 50\% de las candidaturas de mujeres y hombres (Baleares, Castilla-La Mancha, País Vasco y Andalucía), la Ley Orgánica 3/2007, del 22 de marzo, estableció la democracia paritaria en la participación electoral pero con un marco mínimo de 40-60\% de la representación por razón de género. Paradójicamente, esta regulación legal, señala el autor, no ha representado un avance mínimamente significativo en la composición paritaria de las instancias representativas. El porcentaje de paridad, 36\%, no se ha movido pero sí se ha descendido en la clasificación mundial del pues- 
to 10 al 18 . De ahí la propuesta del autor de establecer el 50\% de paridad como ya sucede en las comunidades autónomas mencionadas.

A partir de 2002 se introdujo por primera vez la posibilidad de evitar la concurrencia a los procesos electorales de partidos políticos relacionados con el terrorismo y que pretenden con su actividad deteriorar o destruir el régimen de libertades o imposibilitar el sistema democrático. Son consideradas conductas contrarias al sistema democrático: justificar o exculpar los atentados, fomentar o legitimar la violencia, apoyar políticamente la acción de organizaciones terroristas.

\section{La campaña electoral}

La LOREG define a la campaña electoral como el conjunto de actividades lícitas llevadas a cabo por los candidatos, partidos, federaciones o agrupaciones en orden a la captación de sufragios. Al efecto, el autor destaca tres elementos: uno finalista, otro subjetivo y uno más temporal. Son actividades directamente destinadas a la captación de sufragios (elemento finalista) lo que las distingue de las campañas institucionales; sólo los contendientes electorales pueden hacerla (elemento subjetivo), y son periodos del proceso electoral perfectamente definidos (elemento temporal), en el que por cierto se crea un régimen distinto en la denominada precampaña.

Los poderes públicos pueden realizar durante el periodo electoral una campaña de carácter institucional destinada a informar sobre la fecha de la votación, el procedimiento para votar y los requisitos y trámite de voto por correo, sin influir, en ningún caso, en el voto de los electores. Desde la convocatoria de las elecciones hasta su celebración, se prohíbe cualquier tipo de campaña de logros de los poderes públicos, así como cualquier acto de inauguración de obras y servicios. A consulta del Ministerio del Interior respecto de las campañas que los poderes públicos pueden realizar en periodos electorales, la JEC estableció en un trascendental acuerdo, sin perjuicio de reservarse el análisis en cada caso concreto: "Las que puedan resultar imprescindibles para la salvaguarda del interés público o para el correcto desenvolvimiento de los servicios públicos". Lo que sin embargo, en opinión del autor, ha originado una doctrina de la JEC un tanto errática e impredecible.

La campaña electoral en sentido estricto es analizada por el autor a partir de los sujetos de la regulación, los límites temporales y lo que 
llama el problema de la precampaña, así como la propaganda electoral y la información electoral. Por cuanto a los sujetos, el criterio general es que sólo los contendientes pueden realizar actos de campaña, lo que parece impedir a otras personas físicas o jurídicas la realización de campañas a favor o en contra de los contendientes, "sin perjuicio de lo establecido en el artículo 20 de la Constitución” como lo previene la propia disposición de la LOREG.

En el caso de las precampañas, el autor señala que antes de la convocatoria formal de elecciones no existe, jurídicamente hablando, precampaña. Esto no impide que los partidos políticos puedan tener una intensa actividad electoral meses antes de la convocatoria de cada uno de los procesos electorales, pero es una materia - advierte- que no se somete a la normativa de la LOREG en el doble sentido de que no son actos susceptibles de control por parte de la Administración electoral, y que en forma alguna pueden ser considerados gastos a efectos de subvenciones públicas electorales.

Hasta antes de la reforma de 2011, la LOREG hacía una clara diferenciación en el régimen jurídico de la propaganda electoral y de la información electoral. A partir de 2011, además de la equiparación tendencial entre medios públicos y privados de comunicación, el autor destaca la exigencia de igualdad y proporcionalidad que acerca inexorablemente el régimen de la información al de la publicidad electoral. Al grado que, en opinión del autor, la información electoral deja de estar regulada por criterios relacionados con la libertad de información y es sometida a un estrecho criterio de proporcionalidad de los resultados electorales.

Las candidaturas pueden contratar publicidad electoral en la prensa y en las radios privadas, con un límite del $20 \%$ de los gastos electorales. No pueden contratar espacios de publicidad electoral en los medios de comunicación de titularidad pública ni en las emisoras de televisión privada.

\section{Proclamación de electos}

El escrutinio en las mesas se realiza inmediatamente después de concluir la votación en un acto único que no puede ser interrumpido. Es un acto público y el número de personas que pueden asistir está limitado solamente por las condiciones del local, pero el presidente tiene la facultad de conservar el orden público, limitar el número de 
asistentes y expulsar a quienes obstaculicen el escrutinio. La normativa española no prevé la existencia de observación electoral distinta de los propios partidos contendientes a este acto, por lo tanto a diferencia de otros países no ha habido observadores extranjeros.

En el supuesto más común de que haya varias elecciones, el escrutinio se inicia con las del Parlamento Europeo, después las del Congreso, el Senado, las entidades locales, las de las Asambleas Legislativas de las Comunidades Autónomas y concluye con las de los Cabildos Insulares. Terminado el recuento de los votos emitidos, la Mesa confronta el total de papeletas con el de votantes anotados en la lista del Censo que hayan votado. El presidente pregunta si existe alguna protesta contra el escrutinio; las reclamaciones sólo pueden ser formuladas por los representantes de las candidaturas, representantes e interventores de las mismas o por los candidatos. La expresión de protestas formales en este momento es fundamental para el desarrollo posterior del escrutinio general y de los eventuales recursos contencioso-electorales. Se procede después a la destrucción de las papeletas conservándose sólo sobre las que se hayan producido reclamaciones y las nulas.

Se elabora un acta de escrutinio y después un acta de la sesión; la documentación electoral se distribuye en tres sobres. El primero contiene el original del acta de constitución de la mesa y el acta de la sesión, con los documentos a que éstas hagan referencia y la lista del Censo utilizada; este sobre es entregado al juez de Primera Instancia de la demarcación, y si hay varios al designado por las Juntas electorales. El juez lo debe llevar personalmente a la sede de la Junta Electoral que realizará el escrutinio. El segundo sobre con copia de las actas mencionadas es entregado al juez para que quede en los archivos del juzgado. Un tercer sobre con igual contenido que el segundo es entregado en la propia Mesa a un funcionario de Correos para ser enviado al día siguiente a la Junta Electoral.

La proclamación provisional de los resultados la realiza el gobierno en todos los procesos electorales de alcance nacional, apenas unas horas después de concluidas las votaciones.

Frente al acta de escrutinio cabe un recurso ante la JEC que se presenta ante la Junta que realiza el escrutinio. En ningún caso se realiza un nuevo escrutinio. Una vez resueltos los eventuales recursos, la Junta escrutadora culmina la vía administrativa mediante un Acta de Proclamación de electos, y se abre la posibilidad de la correspondiente vía judicial. 
Esta revista forma parte del acervo de la Biblioteca Jurídica Virtual del Instituto de Investigaciones Jurídicas de la UNAM

Los recursos contra la proclamación de electos pueden ser el contencioso-electoral y el amparo contencioso electoral. Al tenor del artículo 109 de la LOREG "pueden ser objeto de recurso electoral los acuerdos de las Juntas Electorales sobre la proclamación de electos, así como la elección y proclamación de los Presidentes de las Corporaciones locales"; se trata de un procedimiento exclusivo porque las Juntas electorales no pueden admitir reclamación o recurso alguno y porque sólo son reclamables por este procedimiento los actos de proclamación de electos y ningún otro acto electoral. Cualquier otro tipo de irregularidad acontecida durante el proceso deberá seguir el procedimiento ordinario ante los tribunales y, con posterioridad, el recurso de amparo también ordinario.

La jurisprudencia del Tribunal Constitucional ha ido delimitando los principios que en relación a este procedimiento han de regir la actividad de las Salas de lo Contencioso. Entre ellos conviene destacar los siguientes: plena jurisdicción y búsqueda de la verdad material; no sujeción al principio dispositivo, y necesidad de motivación. Por cuanto al contenido de la sentencia, el artículo 113 de la LOREG dispone que la sentencia habrá de pronunciar alguno de los siguientes fallos: inadmisibilidad del recurso; validez de la elección y de la proclamación de electos; nulidad del acuerdo de proclamación de uno o varios electos y proclamación como tal de aquél o aquéllos a quien corresponda, y nulidad de la elección, cuyo alcance puede conducir a la necesidad de repetir la elección así como el alcance de ésta.

El artículo 114.2 de la LOREG establecía en su redacción inicial que contra las sentencias que resuelven los recursos contenciosos electorales no procede recurso alguno ordinario ni extraordinario, salvo el de aclaración. La LO 8/91 añadió: "Y sin perjuicio del recurso de amparo ante el Tribunal Constitucional. El amparo debe solicitarse en el plazo de tres días y el Tribunal Constitucional debe resolver sobre el mismo en los quince días siguientes".

Finalmente, el autor cuya obra se reseña señala que el artículo 108.8 de la LOREG establece como norma general aplicable a todos los cargos públicos representativos, que en el momento de su toma de posesión y para adquirir la plena posesión de sus cargos, los candidatos electos deben jurar o prometer acatamiento a la Constitución. El contexto social e histórico de cada país le da un sentido y aplicación diferente a la misma disposición. En España, tiene una implicación relacionada con la lucha contra el terrorismo, a lo que ya nos hemos referido. En Méxi- 
co, con motivo de las reformas constitucionales de 2011 en materia de amparo y de derechos humanos, la resolución de la Suprema Corte de Justicia de la Nación en el expediente Varios 912/2010, así como la jurisprudencia nacional y de la Corte Interamericana de Derechos $\mathrm{Hu}-$ manos, la misma disposición nos lleva a pensar en el control difuso de la constitucionalidad y de la convencionalidad en materia de derechos humanos, en virtud del nuevo paradigma jurídico que todo aquello entraña. Pero se trata de una historia, otra, que apenas empieza en México.

\section{Eduardo de Jesús Castellanos Hernández}

Investigador en el Instituto de Investigaciones Jurídicas de la UNAM 